\section{Population boom blunts Pakistan's self-sufficiency drive}

Despite Pakistan's efforts to become selfsufficient in food grain, it is still falling short of the target every year. The resulting heavy expenditure on the import of wheat, the staple foodstuff, is compounded by considerable congestion at the port of Karachi and in trains carrying the millions of tons of wheat grain upcountry. The whole economy of Pakistan is suffering in consequence. Last year, for example, wheat created a crisis when the country had a bad harvest and imports rose to 2.3 million tons. The problem is not that production strategy is failing for a valid reason - such as targets being unrealistic or the potential being weak but that the mechanism is inefficient and the will is missing for many imperative measures. These include the package of improved technology for different areas of Pakistan (a target now well within reach) and a streamlining of the distribution of seeds, fertilizers, pesticides and water to the farmer.

At the International Seminar on Wheat held in Islamabad last August, Dr Norman Borlaug, the Nobel laureate, said that at present only one-third of Pakistan's potential wheat production is being exploited. Borlaug, who has been intimately associated with the Green Revolution in Pakistan, blamed the existing official apparatus both for neglecting to apply the available improved technology to wheat production, and for the continued short-sighted reliance upon food aid and concessional purchases (under easy payment contracts from friendly countries, such as the US PL-480).

The pity is that Pakistan also happens to be one of the few countries that staged the Green Revolution early, in the mid-1960s. It had such tempo and potential that Borlaug at that time not only forecast selfsufficiency in food grain within a few years time, but also called Pakistan the 'Mexico of Asia', visualising that it would be exporting wheat and rice to other countries sooner than many imagined. Borlaug's dream was never realised; and sooner than elsewhere, the Green Revolution tapered off.

This is clearly borne out by the wheat production figures since 1965, when the dwarf, high-yield seeds from Mexico became available for commercial sowing.

It can be seen from the accompanying table that wheat production, after nearly doubling from 3.75 million tons in 1965 to 7.10 in 1969, has almost flattened off during the course of the last decade - last year even showing an alarming dip.

Self-sufficiency in wheat could have been attained, even with the very modest increase recorded in the last ten years, but for two inhibiting factors. One is the population explosion, running at a 3\% per annum, a result of the slowly growing standard of living. The per capita daily wheat consumption has risen from 244 to $340 \mathrm{~g}$ during the last 10 years. Even with a record wheat harvest of almost 10 million tons this year, a short-fall of 0.6 million tons is still possible.

There is however hope that, unless the political situation deteriorates further, Pakistan may now be able to turn the corner. The new factor is a drastic reorganisation of the Pakistan Agricultural Research Council (PARC), which has turned it into a fully autonomous organisation with wide powers of planning, coordination, financing and formulating national strategy for agricultural research. The PARC now has a full-time chairman, with the status of secretary to the government. It is also intended that the should be a scientist of high repute and not a politician. The present chairman, Dr Amir Muhammad, has gained the necessary experience and expertise to organise research on a national level through his previous positions as Vice-chancellor of an agricultural university and Director of the Atomic Energy Agricultural Research Institute.

The PARC is now equipped to provide leadership to other research organisations in the field. This is particularly significant in Pakistan, where agricultural research has largely been fragmented at the provincial level and has lacked direction. This was all too manifest last year in the wheat production debacle. Farmers had sown considerable amounts of wheat varieties that were susceptible to disease, even though disease-resistant types could have been easily identified and the farmer suitably advised - if the research organisations and their provincial extension services had been alive to the situation.

This year's 20\% increase in wheat output is partly due to the PARC reorganisation, and partly to the federal government itself. After recovering from the panic of having to import 2.3 million tons of wheat, and paying the heavy price, the government is now taking an active interest.

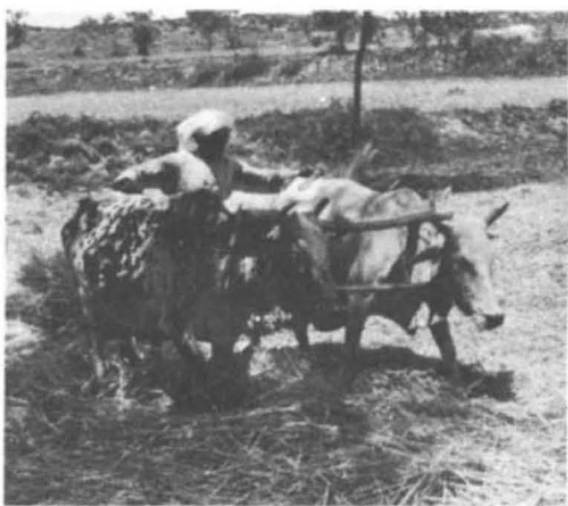

The PARC has started taking such vital steps as zoning the country for some of the major crops in terms of agro-ecological variations, sending its research teams in different zones to conduct investigations and research on the spot, and providing analytical service facilities not available at the provincial institutes. But its most significant achievement appears to be the establishment of properly constituted National Agricultural Research Centre near Islamabad. A staff of 25 scientists, eight of them postdoctoral, are already working at the centre, with another 40 in the process of recruitment. The emphasis is on high calibre to strengthen the team.

The centre has already mounted a large number of experiments on its own fields (which cover 1,500 acres) involving topics such as plant genetics, agronomy, and plant pathology. It is also investigating the 'package technology' of producing different grains for different areas. Each package will contain information on varieties, cultural practices, fertilizers, weed control, harvesting, and storage.

Genetic resources conservation is another vital responsibility of the centre. It has already collected thousands of exotic, as well as local, varieties of wheat, rice, triticale, maize and other grains. They will be preserved for up to 100 years in the main depository, in vacuum at $0^{\circ} \mathrm{C}$. To mount an effective genetic variety programme, the breeding stock should have great genetic diversity; breeders all over the world have started to feel the pinch of starvation as new sources of genetic diversity are getting scarce, squeezed out by the rapidly spreading improved crop plant varieties.

Axim Kidwai 